\title{
High prevalence and undertreatment of osteoporosis in elderly patients undergoing total hip arthroplasty
}

\author{
M.M. Delsmann ${ }^{1} \cdot$ A. Strahl ${ }^{2} \cdot$ M. Mühlenfeld ${ }^{2} \cdot$ N.M. Jandl ${ }^{2}$ F.T. Beil ${ }^{2} \cdot$ C. Ries ${ }^{2} \cdot$ T. Rolvien $^{2}$
}

Received: 25 November 2020 / Accepted: 5 February 2021 / Published online: 11 February 2021

(C) The Author(s) 2021

\begin{abstract}
Summary We detected a high prevalence of low bone mineral density assessed by DXA in 268 elderly patients with end-stage osteoarthritis scheduled for total hip arthroplasty (18\% osteoporosis, $41 \%$ osteopenia). Therefore, and due to the identified concomitant undertreatment, routine DXA measurements should be considered in elderly patients prior to surgery.

Introduction Bone quality represents a decisive factor for osseointegration, durability, and complications of an implanted prosthesis. Although the risk of osteoporosis increases with age and the assessment of bone mineral density (BMD) prior to total hip arthroplasty (THA) is recommended in elderly patients, a systematic, unbiased analysis of such patients is not available in the literature.

Methods In this retrospective study, we examined 268 elderly patients (age $\geq 70$ years) who underwent dual-energy X-ray absorptiometry (DXA) within 3 months prior to primary THA. Demographics, medical history, radiographic OA grade, and stem fixation method (i.e., cemented or cementless) were obtained.

Results In total, 153 (57\%) cemented and 115 (43\%) cementless stem fixations during THA were performed. Forty-nine patients $(18 \%)$ were diagnosed with osteoporosis (T-score $\leq-2.5$ ), 110 patients $(41 \%)$ with osteopenia (T-score $\leq-1.0$ ), and 109 patients $(41 \%)$ with normal BMD (T-score $>-1.0)$. Importantly, 36/49 patients $(73 \%)$ with osteoporosis were not diagnosed before, resulting in a relevant undertreatment. Female sex and low body mass index (BMI) were the main factors negatively influencing the bone mineral density (BMD).

Conclusions Due to a high incidence of undiagnosed and untreated osteoporosis in elderly patients with potential effects on the success of osseointegration as well as other clinical outcomes, DXA measurements should be included in the clinical routine for these patients prior to THA.
\end{abstract}

Keywords Arthroplasty $\cdot$ Bone mineral density $\cdot$ DXA $\cdot$ Osteoarthritis $\cdot$ Osteoporosis

\section{Introduction}

Total hip arthroplasty (THA) is a highly successful surgical intervention to restore the function of the hip joint and to relieve pain in patients with symptomatic end-stage osteoarthritis (OA) of the hip [1]. As age represents not only one of the most relevant risk factors for OA but also for osteoporosis,

T. Rolvien

t.rolvien@uke.de

1 Department of Osteology and Biomechanics, University Medical Center Hamburg-Eppendorf, Hamburg, Germany

2 Division of Orthopaedics, Department of Trauma and Orthopaedic Surgery, University Medical Center Hamburg-Eppendorf, Hamburg, Germany there is a general recommendation from the International Society for Clinical Densitometry (ISCD) to assess bone mineral density (BMD) in women aged $\geq 65$ years and men aged $\geq 70$ years prior to THA [2]. Nonetheless, an implementation of this recommendation is not consistently carried out in clinical routine. Namely, although it is generally considered as relevant and $60 \%$ of the orthopedic surgeons previously stated that a low BMD represents a reason to reconsider their choice of prosthesis fixation during THA, only $4 \%$ performed BMD measurements preoperatively [3]. At present, the decision whether to perform cemented or cementless fixation during THA usually depends on the surgeon's preference, regionspecific standards, the age of the patient, as well as the intraoperative impression of bone quality [4], but is usually not based on bone mineral density (BMD) in a standardized or routine manner. 
In patients with $\mathrm{OA}$, a high frequency of osteopenia and osteoporosis has previously been reported, but limited patient numbers, restriction to one sex, and lack of differentiation between hip or knee arthroplasty were limiting factors [5-8]. Patients with low BMD possess increased risks for major potential complications in the context of a THA: intraoperative fractures, periprosthetic fractures, stem subsidence, and aseptic loosening [9-12].

In the present study, we analyzed the BMD assessed by dual-energy X-ray absorptiometry (DXA) in elderly OA patients aged $\geq 70$ years scheduled for THA. We hypothesized that osteoporosis is a relevant and frequent finding, which may underline the need for routine BMD measurements prior to surgery. An additional aim was to investigate the relevance of potential influencing factors on BMD in these patients.

\section{Methods}

\section{Study cohort}

We retrospectively included 268 consecutive elderly patients aged $\geq 70$ years who underwent THA in our department due to end-stage OA in the years 2018 and 2019. The only exclusion criteria were active cancer with skeletal metastases and inoperability due to severe medical conditions. We assessed demographic parameters (sex, age, and BMI) as well as the preoperative BMD determined by DXA as a part of the routine workup in all patients. In patients diagnosed with osteoporosis and/or indication for specific osteoporosis drug treatment such treatment was initiated or recommended according to the German osteoporosis guidelines [13]. Furthermore, the detailed medical history with primary focus on relevant clinical risk factors for osteoporosis and increased fracture risk was obtained. These risk factors included the presence of previous fractures, rheumatoid arthritis, oral intake of glucocorticoids for longer than 3 months in the past or at present, as well as regular consumption of alcohol (more than three units per day) and tobacco. The presence of diabetes mellitus was also recorded. Regarding the severity of OA, the Kellgren-Lawrence score was determined in preoperative radiographs [14]. Moreover, we evaluated the type of femoral stem fixation (cemented or cementless). Either the CORAIL stem (Depuy Synthes, Raynham, MA, USA; cemented or cementless) or the Müller Geradschaft (cemented)/CLS Spotorno (cementless) (Zimmer-Biomet, Warsaw, IN, USA) was implanted. The acetabular cup was implanted without the use of bone cement (cementless) in all cases. The orthopedic interventions were performed by senior surgeons only. Preoperative DXA results were not included in the surgeon's decision to perform cemented or cementless stem fixation in a routine or standardized manner. This multifactorial process was based on age, sex, BMD, femur geometry, and intraoperative impression of bone quality. The present study is in accordance with the guidelines of the local ethics committee. Since a retrospective chart analysis with anonymized data was performed in all study patients, the need for ethical approval was waived.

\section{Dual-energy X-ray absorptiometry}

We assessed the bone mineral density (BMD) at the left and right proximal femur and the lumbar spine (L1-L4) by using dual-energy X-ray absorptiometry (DXA) within 3 months before surgery (Lunar Prodigy enCore 2007, GE Healthcare; Madison, WI, USA). This instrument-based assessment was performed according to the German osteoporosis guidelines (DVO). The T-scores representing the BMD standard deviations above or below the mean for young, sex-matched healthy adults were generated by the manufacturer's software. In accordance with the guidelines of the World Health Organization (WHO), we diagnosed osteoporosis and osteopenia on the basis of the $\mathrm{T}$-score (osteoporosis T-score $\leq-2.5$, osteopenia T-score $>-2.5 \leq-1.0$, normal T-score $>-1.0$ ).

\section{Statistical analysis}

We used SPSS $®$ statistical program (version 26.0, IBM, Armonk, NY, USA) and GraphPad Prism ${ }^{\circledR}$ (version 7.0, GraphPad Software, La Jolla, CA) for statistical analyses. Continuous variables are expressed as mean \pm standard deviation (SD), while categorical variables are expressed as number and percentage. Evaluation of normality of data distribution was tested with the Shapiro-Wilk test. For determining the age-dependent development of T-scores, we performed linear regression analysis and determined the $p$-value, the coefficient of determination $R^{2}$, and the $95 \%$ confidence interval (CI) of the respective regression slopes. Group differences were tested for significance using unpaired two-sided $t$-test for normally distributed data and Mann-Whitney $U$ test for non-normally distributed data. Differences of more than two groups were analyzed by one-way ANOVA with Tukey's post hoc analysis for multiple comparisons in the case of normally distributed data. For non-normally distributed data, the Kruskal-Wallis test with Dunn's post hoc test for multiple comparisons was performed. To determine the influence of age, sex, BMI, or Kellgren-Lawrence score on BMD T-score, a multivariate regression model was performed. The regression used the "Enter" method to examine the significant impact of all variables simultaneously. $P$-values $<0.05$ (2-tailed) were considered statistically significant. 


\section{Results}

The study collective of hip OA patients undergoing cemented or cementless THA $(n=268)$ consisted of $90(34 \%)$ male and $178(66 \%)$ female patients (Fig. 1a-c). Male and female patients were similar in age, but the BMI values differed significantly between the sexes, with values of $28.0 \pm 3.0 \mathrm{~kg} / \mathrm{m}^{2}$ for male patients and $27.2 \pm 4.6 \mathrm{~kg} / \mathrm{m}^{2}$ for female patients $(p=0.029)$ (Table 1). Regarding the relevant clinical risk factors for osteoporosis, no differences were present between male and female patients. A total of $15(5.6 \%)$ patients had previously suffered from a fragility fracture (24 fractures in total). Of these, 10/24 fractures occurred at a peripheral site, while 14/24 were vertebral fractures. Furthermore, 17 patients (6.3\%) had a confirmed diagnosis of rheumatoid arthritis, while 13 patients (4.9\%) were exposed to oral glucocorticoids for longer than three months in the past or present. Thirty-nine patients $(14.6 \%)$ with diabetes mellitus were identified.
Regarding tobacco and alcohol consumption, 19 patients stated to drink more than three units of alcohol per day, while 27 patients were currently smoking.

To determine the skeletal status, we measured the BMD and the associated T-scores by DXA of both hips and the lumbar spine. An overview of the demographic and diseasespecific characteristics, medical history including risks factors, and DXA results for female and male patients is given in Table 1. Importantly, of the 268 patients analyzed, 49 patients $(18 \%)$ were diagnosed with osteoporosis, while 110 patients $(41 \%)$ had T-scores in the range of osteopenia, resulting in a total number of 159 patients $(59 \%)$ with reduced BMD (Fig. 1d). Of the 49 patients with osteoporosis, only 13 (27\%) had already been diagnosed with osteoporosis before (Fig. 1e). Of note, only 18 (37\%) patients received vitamin D $\left(25(\mathrm{OH}) \mathrm{D}_{3}\right)$ supplementation (Fig. 1f), and an antiresorptive treatment had been prescribed to only eleven (22\%) patients (Fig. 1g), indicating relevant undertreatment.
Table 1 Demographic and disease-specific characteristics, medical history, and DXA evaluation in the OA patient collective scheduled for THA $(n=268)$

\begin{tabular}{|c|c|c|c|}
\hline & $\begin{array}{l}\text { Female } \\
\text { Mean (SD) or } n(\%)\end{array}$ & $\begin{array}{l}\text { Male } \\
\text { Mean (SD) or } n(\%)\end{array}$ & $p$-value \\
\hline Total & $178(66 \%)$ & $90(34 \%)$ & \\
\hline \multicolumn{4}{|l|}{ Patient characteristics } \\
\hline Age (years) & $78.6(4.7)$ & $77.6(5.0)$ & 0.076 \\
\hline Height $(\mathrm{cm})$ & $163.8(5.9)$ & $174.0(7.5)$ & $<0.0001$ \\
\hline Weight (kg) & $73.4(14.7)$ & $85.1(11.3)$ & $<0.0001$ \\
\hline BMI $\left(\mathrm{kg} / \mathrm{m}^{2}\right)$ & $27.2(4.6)$ & $28.0(3.0)$ & 0.029 \\
\hline Kellgren-Lawrence Score & $3.1(0.6)$ & $3.3(0.5)$ & 0.068 \\
\hline Cemented femoral stem fixation & $111 / 178(62.4 \%)$ & $42 / 90(46.7 \%)$ & $\mathbf{0 . 0 1 4}^{\#}$ \\
\hline \multicolumn{4}{|l|}{ Medical history and risk factors } \\
\hline Previous fractures & $11 / 178(6.2 \%)$ & $4 / 90(4.4 \%)$ & $0.559^{\#}$ \\
\hline $\begin{array}{l}\text {-Peripheral } \\
\text {-Vertebral }\end{array}$ & $\begin{array}{l}6 / 178(3.4 \%) \\
5 / 178(2.8 \%)\end{array}$ & $\begin{array}{l}2 / 90(2.2 \%) \\
2 / 90(2.2 \%)\end{array}$ & \\
\hline Rheumatoid arthritis & $8 / 178(4.5 \%)$ & $9 / 90(10.0 \%)$ & $0.081^{\#}$ \\
\hline Diabetes mellitus & $24 / 178(13.5 \%)$ & $15 / 90(16.7 \%)$ & $0.485^{\#}$ \\
\hline $\begin{array}{l}\text {-Type } 1 \\
\text {-Type } 2\end{array}$ & $\begin{array}{l}3 / 178(1.7 \%) \\
21 / 178(11.8 \%)\end{array}$ & $\begin{array}{l}0 / 90(0 \%) \\
15 / 90(16.7 \%)\end{array}$ & \\
\hline Glucocorticoids & $9 / 178(5.1 \%)$ & $4 / 90(4.4 \%)$ & $0.825^{\#}$ \\
\hline Three or more units alcohol/day & $10 / 178(5.7 \%)$ & $9 / 90(10.0 \%)$ & $0.186^{\#}$ \\
\hline Current smoking & $17 / 178(9.6 \%)$ & $10 / 90(11.1 \%)$ & $0.688^{\#}$ \\
\hline \multicolumn{4}{|l|}{ DXA results } \\
\hline T-score hip (min.) & $-1.5(1.3)$ & $-0.7(1.3)$ & $<0.0001$ \\
\hline T-score affected hip & $-1.0(1.3)$ & $-0.3(1.3)$ & $<0.0001$ \\
\hline T-score unaffected hip & $-1.1(1.3)$ & $-0.4(1.3)$ & 0.001 \\
\hline T-score lumbar spine & $-0.7(1.8)$ & $0.8(2.1)$ & $<0.0001$ \\
\hline Osteoporosis $(\mathrm{T}$-score $\leq-2.5)$ & $41 / 178(23 \%)$ & $8 / 90(9 \%)$ & $0.005^{\#}$ \\
\hline Osteopenia $($ T-score $\leq-1.0>-2.5)$ & $81 / 178(46 \%)$ & $29 / 90(32 \%)$ & $\mathbf{0 . 0 3 7 ^ { \# }}$ \\
\hline Normal (T-score $>-1.0)$ & $56 / 178(31 \%)$ & $53 / 90(59 \%)$ & $<0.0001^{\#}$ \\
\hline
\end{tabular}

${ }^{\#}$ Determined by the chi ${ }^{2}$ test. Bold indicates significant differences $(\mathrm{p}<0.05)$.

THA total hip arthroplasty, $B M I$ body mass index, $S D$ standard deviation, $n$ number of patients, min. minimum 

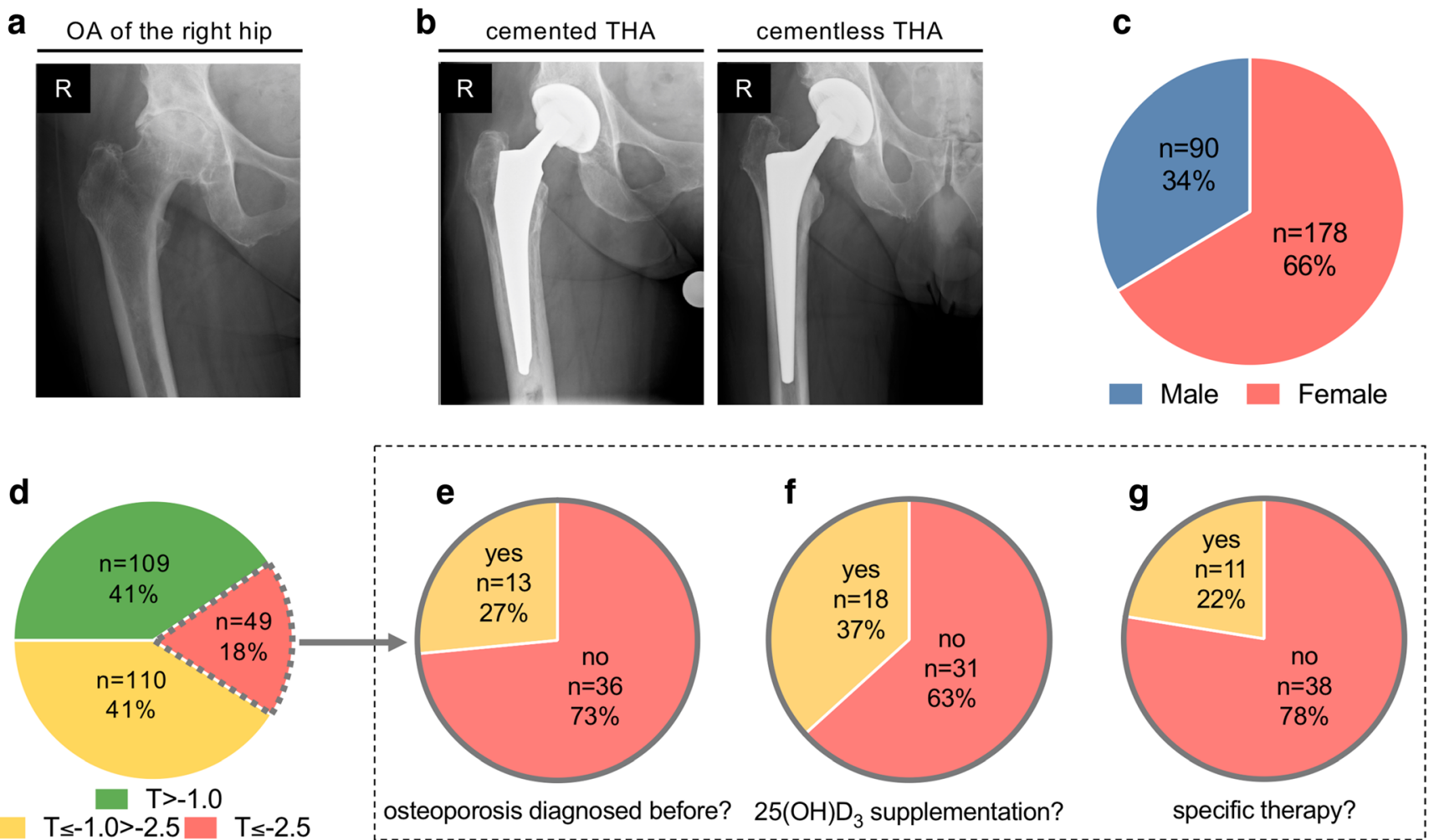

Fig. 1 Overview of the study collective and DXA results in THA patients aged $\geq 70$ years. a Representative preoperative radiograph (right hip AP) of an OA patient included in this study. $\mathbf{b}$ Postoperative radiographs (right hip AP) of a cemented and a cementless THA. c Sex distribution of the study population. $\mathbf{d}$ Pie charts showing DXA results and categorization in

Analyzing the influencing factors of BMD, especially of the hips as the region of interest in THA, the sex-specific distribution of BMD showed significantly higher T-scores in male individuals compared to females $(p<0.0001$; Fig. $2 \mathrm{a})$, resulting in a lower frequency of low bone mass (i.e., osteoporosis) than in females. Namely, osteoporosis by T-score ${ }_{\min }$ was observed in only 8/90 (9\%) of the male and 41/178 (23\%) of the female patients (Table 1). When examining a possible
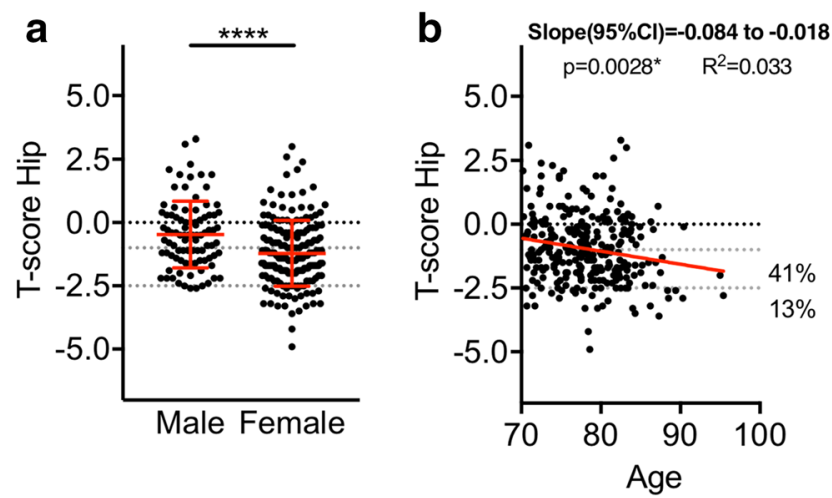

Fig. 2 Influencing factors on BMD values at the hip. a In the patient collective of OA patients $\geq 70$ years, significantly lower T-scores at the hip could be revealed in females compared to males (Mann-Whitney $U$ test). b Furthermore, age (years) showed a weak negative association with the $\mathrm{T}$-score at the hip (linear regression). c A moderate positive osteoporosis, osteopenia, or bone mineral density within the reference

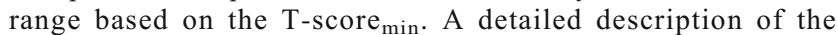
osteoporosis patients concerning e an existing diagnosis of osteoporosis, $\mathbf{f}$ the current supplementation of vitamin D, and the $\mathbf{g}$ application of a bone-specific therapy

age-related BMD loss of the hips in our patient collective, linear regression analysis revealed a weak negative association of age with T-scores in the hip $\left(R^{2}=0.033 ; p=0.003\right.$, slope $(95 \% \mathrm{CI})=-0.084$ to $-0.018 \mathrm{~T}$-score per year) (Fig. $2 \mathrm{~b})$. However, a moderate positive association was found with relation to BMI with an increased T-scores of the hips in patients with a higher BMI $\left(R^{2}=0.209 ; p<0.0001\right.$, slope $(95 \% \mathrm{CI})=0.114$ to $0.185 \mathrm{~T}$-score per $\mathrm{kg} / \mathrm{m}^{2}$; Fig. $\left.2 \mathrm{c}\right)$. No
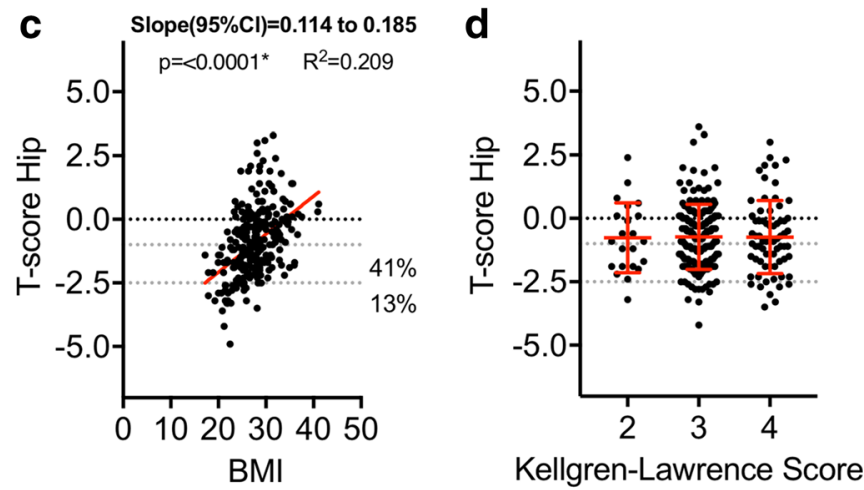

association was detected between BMI and T-score at the hip (linear regression). d T-scores of the affected hip were not different between the different OA grades determined by the Kellgren-Lawrence scores (Kruskal-Wallis test). $* * * * p<0.0001$ 
Table 2 Multivariate regression model analyzing the independent factors influencing BMD

\begin{tabular}{|c|c|c|c|c|c|c|c|c|c|}
\hline & \multicolumn{3}{|c|}{$\mathrm{T}^{- \text {score }_{\min }}$} & \multicolumn{3}{|c|}{ T-score ${ }_{\text {aff. }}$} & \multicolumn{3}{|c|}{ T-score LS $_{\text {S }}$} \\
\hline & $\beta$ & $T$ & $p$ & $\beta$ & $T$ & $p$ & $\beta$ & $T$ & $p$ \\
\hline \multicolumn{10}{|l|}{ Hip } \\
\hline (Intercept) & & -0.488 & 0.626 & & 0.015 & 0.998 & & -0.174 & 0.862 \\
\hline Age & -0.087 & -1.552 & 0.122 & -0.105 & -1.793 & 0.074 & -0.052 & -0.908 & 0.365 \\
\hline Sex & -0.255 & -4.639 & $<0.001$ & -0.223 & -3.890 & $<0.001$ & -0.308 & -5.458 & $<0.001$ \\
\hline BMI & 0.357 & 6.439 & $<0.001$ & 0.308 & 5.314 & $<0.001$ & 0.293 & 5.161 & $<0.001$ \\
\hline KLS & -0.041 & -0.740 & 0.460 & 0.001 & 0.026 & 0.980 & 0.017 & 0.303 & 0.762 \\
\hline$R^{2}$ adjusted & $0.22 * *$ & & & $0.169 * *$ & & & $0.2 * *$ & & \\
\hline
\end{tabular}

Bold indicates significant independent predictors

$* * p<0.001$ for the multivariate ANOVA regression model

-score $_{\min }$ minimum T-score of both hips, $T$-score aff. $_{\text {T-score of the affected/operated hip, } T \text {-score }}$ LS $\mathrm{T}$-score lumbar spine, KLS Kellgren-Lawrence score, $B M I$ body mass index differences in T-scores were found between the groups of different OA severity grades classified according to the Kellgren-Lawrence score (Fig. 2d).

In line to these results, a multivariate regression analysis to determine the influence of age, sex, BMI, and KellgrenLawrence score on BMD indicated that sex and BMI were statistically significant independent factors influencing the T-score in our elderly patient collective with OA (Table 2). Specifically, female sex and low BMI predicted lower Tscores in total, in the affected hip and in the lumbar spine $(p<0.001)$. Age and the severity of OA did not represent independent determinants.

\section{Discussion}

During the process of osseointegration of implants, which is based on bony ingrowth in the porous surface of the implant, the bone quality and remodeling capacities are of great importance [15]. In the case of reduced BMD, extensive micromovements and the risk of increased migration with subsequent loss of optimal implant position can decisively impair osseointegration leading to implant failure [16, 17]. In cementless THA, especially the initial stem stability is an essential factor in forming a sufficient fixation between the bone and the prosthesis [18]. Other potential complications of reduced BMD in the context of cementless THA are the increased risk of intraoperative periprosthetic fractures and aseptic loosening [12, 19, 20]. A substantial influence of the BMD on the success or failure of the cementless THA appears therefore evident. Furthermore, large registry studies previously showed that the risk of intraoperative periprosthetic fracture is markedly higher in cementless stems [21, 22]. Nonetheless, and despite recommendation from the International Society for Clinical Densitometry (ISCD), in women aged $\geq 65$ years and men aged $\geq 70$ years, BMD measurements are not usually implemented in routine examinations prior to THA and consequently are not included in the decision-making process whether to perform cemented or cementless fixation in THA. In the present study, we demonstrated that osteoporosis assessed by DXA is highly prevalent and undertreated in elderly patients undergoing THA.

From the 268 patients included, 49 (18\%) had osteoporosis and $110(41 \%)$ had osteopenia expressed by a T-score of $\leq-2.5$ and $\leq-1.0$, respectively. Previous studies also analyzed the BMD of patients undergoing total joint arthroplasty by DXA with an osteoporosis frequency of 25-33\%. However, these previous studies were limited to low patient numbers, the examination of exclusively female patients scheduled for cementless THA, or a lack of differentiation between hip and knee arthroplasty [5-8]. Since we have measured a consecutive series of patients $\geq 70$ years of age using DXA, we believe that the detected osteoporosis and osteopenia frequency of $18 \%$ and $41 \%$ shown here reflects a realistic prevalence of elderly OA patients in central Europe affected by osteoporosis. Global differences in the incidence of osteoporosis must be considered.

Analyzing the potential risk factors, sex and BMI were the main factors influencing BMD in our patient collective, as confirmed by the multivariate regression analysis. Therefore, especially women with low BMI were at high risk of having a low BMD within our elderly patient collective of OA patients. Interestingly, and despite the fact that osteoporosis risk is known to increase with age, age had no effect on BMD in the patient collective of OA patients $\geq 70$ years, possibly because of the opposing effects of decreasing BMD and increasing degeneration (which positively affects DXA results) with age in this selected group.

Our results are primarily important as $36(73 \%)$ of the 49 patients with osteoporosis had not been diagnosed with osteoporosis before, strengthening the need for routinely performed DXA measurements before surgery. Furthermore, 
the observed problematic undertreatment of patients with osteoporosis regarding vitamin D supplementation (63\% without vitamin D supplementation) as well as bone-specific treatment ( $78 \%$ without bone-specific treatment) became apparent, as all patients with osteoporosis fulfilled the indications for such treatment. The results of the present study have several clinical implications in line with previous studies. Besides the increased risk for atraumatic or low-energy fractures in patients with osteoporosis, the osseointegration of a cementless femoral stem can be impaired by poor bone remodeling capacities [17]. On the other hand, it has already been shown that the treatment with antiresorptive agents such as bisphosphonates and denosumab reduces the risk for an early femoral stem migration in the context of a THA [23-25]. Moreover, both bisphosphonates and denosumab had a significant positive effect on the reduction of periprosthetic bone loss and consequently on the revision rates [19, 23, 26, 27]. In patients with osteoporotic bone, an antiresorptive treatment could therefore be a decisive factor for either success or failure of osseointegration as well as rates of loosening [28]. Based on these collective findings, it appears crucial to identify OA patients undergoing THA with low BMD, in order to initiate adequate treatment. Overall, it is interesting to note that the use of bisphosphonates does not appear to have a significant effect on the progression of the OA of the hip or the risk of undergoing a THA in patients with hip OA [29]. Nevertheless, in the case of knee OA, it has been shown that bisphosphonates seem to delay the progression of $\mathrm{OA}$ and reduce the risk of a total knee arthroplasty [30, 31]. Besides, it should be noted that with the existing endemic vitamin $D$ deficiency in northern Germany [32], vitamin D supplementation is indispensable for osteoporosis therapy to allow balanced calcium homeostasis. Although we were not able to assess preoperative vitamin D levels in all our patients, it is highly likely that vitamin D deficiency was present in the majority of patients. Patients with low BMD were recommended to attend our outpatient clinic for skeletal diseases, where extensive laboratory tests are carried out before initiation or adjustment of vitamin D supplementation as well as bone-specific treatment.

The decision whether to perform cemented or cementless fixation during THA is subject to ongoing discussion and is also influenced by geographical factors. In Germany, the endoprosthesis registry was able to show in over 150,000 included patients that the probability of early failure in patients $\geq 75$ years is significantly higher in patients with cementless compared to cemented stems, while in patients $<75$ years, both fixation methods showed similar results [33]. One of the reasons for this difference could be a higher incidence of low BMD in patients of advanced age. Here, BMD measurements by DXA prior to THA could possibly identify patients who are suitable for cementless implants despite advanced age. In this regard, it is interesting to note that implanting a cemented stem was associated with a $25 \%$ higher load-tofailure force compared to the cementless equivalent in a previous cadaveric study [34]. Considering the high incidence of reduced bone quality in elderly patients in combination with the relevant therapeutic consequences, a general DXA measurement before the surgery in patients $\geq 70$ years of age is likely beneficial to improve short- and long-term treatment outcomes.

\section{Conclusion}

In the present patient collective of end-stage OA patients aged $\geq 70$ years scheduled for THA, there was a high frequency of reduced BMD (i.e., osteoporosis). The majority of these cases had not been diagnosed with osteoporosis before leading to a crucial rate of undertreatment. A general assessment of BMD prior to THA should be considered in patients over 70 years to optimize treatment and outcome, which includes the prevention of complications such as intraoperative periprosthetic fractures and aseptic loosening, and likely also to assist the surgeon's decision to perform cemented or cementless fixation. However, longitudinal studies should assess the effects of low BMD on these complications.

Funding Open Access funding enabled and organized by Projekt DEAL.

\section{Declarations}

Ethical approval A retrospective chart analysis was conducted in all study patients. Data were anonymized before analysis. Therefore, the need of ethic approval was waived.

Informed consent The authors declare that informed consent was obtained in all patients.

\section{Conflicts of interest None.}

Open Access This article is licensed under a Creative Commons Attribution-NonCommercial 4.0 International License, which permits any non-commercial use, sharing, adaptation, distribution and reproduction in any medium or format, as long as you give appropriate credit to the original author(s) and the source, provide a link to the Creative Commons licence, and indicate if changes were made. The images or other third party material in this article are included in the article's Creative Commons licence, unless indicated otherwise in a credit line to the material. If material is not included in the article's Creative Commons licence and your intended use is not permitted by statutory regulation or exceeds the permitted use, you will need to obtain permission directly from the copyright holder. To view a copy of this licence, visit http:// creativecommons.org/licenses/by-nc/4.0/.

Open Access This article is licensed under a Creative Commons Attribution-NonCommercial 4.0 International License, which permits any non-commercial use, sharing, adaptation, distribution and 
reproduction in any medium or format, as long as you give appropriate credit to the original author(s) and the source, provide a link to the Creative Commons licence, and indicate if changes were made. The images or other third party material in this article are included in the article's Creative Commons licence, unless indicated otherwise in a credit line to the material. If material is not included in the article's Creative Commons licence and your intended use is not permitted by statutory regulation or exceeds the permitted use, you will need to obtain permission directly from the copyright holder. To view a copy of this licence, visit http:// creativecommons.org/licenses/by-nc/4.0/.

\section{References}

1. Ferguson RJ, Palmer AJ, Taylor A, Porter ML, Malchau H, GlynJones S (2018) Hip replacement. Lancet 392:1662-1671

2. Anderson PA, Morgan SL, Krueger D, Zapalowski C, Tanner B, Jeray KJ, Krohn KD, Lane JP, Yeap SS, Shuhart CR, Shepherd J (2019) Use of bone health evaluation in orthopedic surgery: 2019 ISCD official position. J Clin Densitom 22:517-543

3. Maier GS, Kolbow K, Lazovic D, Maus U (2016) The importance of bone mineral density in hip arthroplasty: results of a survey asking orthopaedic surgeons about their opinions and attitudes concerning osteoporosis and hip arthroplasty. Adv Orthop 2016: 8079354

4. Konan S, Abdel MP, Haddad FS (2019) Cemented versus uncemented hip implant fixation: should there be age thresholds? Bone Joint Res 8:604-607

5. Makinen TJ, Alm JJ, Laine H, Svedstrom E, Aro HT (2007) The incidence of osteopenia and osteoporosis in women with hip osteoarthritis scheduled for cementless total joint replacement. Bone 40: 1041-1047

6. Bernatz JT, Brooks AE, Squire MW, Illgen RI 2nd, Binkley NC, Anderson PA (2019) Osteoporosis is common and undertreated prior to total joint arthroplasty. J Arthroplasty 34:1347-1353

7. Lingard EA, Mitchell SY, Francis RM, Rawlings D, Peaston R, Birrell FN, McCaskie AW (2010) The prevalence of osteoporosis in patients with severe hip and knee osteoarthritis awaiting joint arthroplasty. Age Ageing 39:234-239

8. Glowacki J, Hurwitz S, Thornhill TS, Kelly M, LeBoff MS (2003) Osteoporosis and vitamin-D deficiency among postmenopausal women with osteoarthritis undergoing total hip arthroplasty. J Bone Joint Surg Am 85:2371-2377

9. Bottai V, Dell'Osso G, Celli F, Bugelli G, Cazzella N, Cei E, Guido G, Giannotti S (2015) Total hip replacement in osteoarthritis: the role of bone metabolism and its complications. Clin Cases Miner Bone Metab 12:247-250

10. Lindberg-Larsen M, Jorgensen CC, Solgaard S, Kjersgaard AG, Kehlet H, Lunbeck Foundation Centre for Fast-track H, Knee R (2017) Increased risk of intraoperative and early postoperative periprosthetic femoral fracture with uncemented stems. Acta Orthop 88:390-394

11. Capone A, Congia S, Civinini R, Marongiu G (2017) Periprosthetic fractures: epidemiology and current treatment. Clin Cases Miner Bone Metab 14:189-196

12. Liu B, Ma W, Li H, Wu T, Huo J, Han Y (2019) Incidence, classification, and risk factors for intraoperative periprosthetic femoral fractures in patients undergoing total hip arthroplasty with a single stem: a retrospective study. J Arthroplasty 34:1400-1411

13. (2017) Prophylaxe, Diagnostik und Therapie der Osteoporose bei postmenopausalen Frauen und Männern. Dachverband der Deutschsprachigen Wissenschaftlichen Osteologischen Gesellschaft. https://www.dv-osteologie.org/uploads/Leitlinie\% 202017/Finale\%20Version\%20Leitlinie\%20Osteoporose\% 202017_end.pdf
14. Kellgren JH, Lawrence JS (1957) Radiological assessment of osteoarthrosis. Ann Rheum Dis 16:494-502

15. Apostu D, Lucaciu O, Berce C, Lucaciu D, Cosma D (2018) Current methods of preventing aseptic loosening and improving osseointegration of titanium implants in cementless total hip arthroplasty: a review. J Int Med Res 46:2104-2119

16. Pilliar RM, Lee JM, Maniatopoulos C (1986) Observations on the effect of movement on bone ingrowth into porous-surfaced implants. Clin Orthop Relat Res 108-113

17. Aro HT, Alm JJ, Moritz N, Makinen TJ, Lankinen P (2012) Low BMD affects initial stability and delays stem osseointegration in cementless total hip arthroplasty in women: a 2-year RSA study of 39 patients. Acta Orthop 83:107-114

18. Gabarre S, Herrera A, Ibarz E, Mateo J, Gil-Albarova J, Gracia L (2016) Comparative analysis of the biomechanical behaviour of two cementless short stems for hip replacement: linea anatomic and minihip. PLoS One 11:e0158411

19. Russell LA (2013) Osteoporosis and orthopedic surgery: effect of bone health on total joint arthroplasty outcome. Curr Rheumatol Rep 15:371

20. Wilkinson JM, Hamer AJ, Rogers A, Stockley I, Eastell R (2003) Bone mineral density and biochemical markers of bone turnover in aseptic loosening after total hip arthroplasty. J Orthop Res 21:691696

21. Abdel MP, Watts CD, Houdek MT, Lewallen DG, Berry DJ (2016) Epidemiology of periprosthetic fracture of the femur in 32644 primary total hip arthroplasties: a 40-year experience. Bone Joint J 98-B:461-467

22. Springer BD, Etkin CD, Shores PB, Gioe TJ, Lewallen DG, Bozic KJ (2019) Perioperative periprosthetic femur fractures are strongly correlated with fixation method: an analysis from the American Joint Replacement Registry. J Arthroplasty 34:S352-S354

23. Aro HT, Nazari-Farsani S, Vuopio M, Loyttyniemi E, Mattila K (2019) Effect of denosumab on femoral periprosthetic BMD and early femoral stem subsidence in postmenopausal women undergoing cementless total hip arthroplasty. JBMR Plus 3:e10217

24. Teng S, Yi C, Krettek C, Jagodzinski M (2015) Bisphosphonate use and risk of implant revision after total hip/knee arthroplasty: a metaanalysis of observational studies. PLoS One 10:e0139927

25. Hilding M, Aspenberg P (2006) Postoperative clodronate decreases prosthetic migration: 4-year follow-up of a randomized radiostereometric study of 50 total knee patients. Acta Orthop 77: 912-916

26. Shi J, Liang G, Huang R, Liao L, Qin D (2018) Effects of bisphosphonates in preventing periprosthetic bone loss following total hip arthroplasty: a systematic review and meta-analysis. J Orthop Surg Res 13:225

27. Lin T, Yan SG, Cai XZ, Ying ZM (2012) Bisphosphonates for periprosthetic bone loss after joint arthroplasty: a meta-analysis of 14 randomized controlled trials. Osteoporos Int 23:1823-1834

28. Khatod M, Inacio MC, Dell RM, Bini SA, Paxton EW, Namba RS (2015) Association of bisphosphonate use and risk of revision after THA: outcomes from a US total joint replacement registry. Clin Orthop Relat Res 473:3412-3420

29. Hung CC, Wang CY, Fu SH, Yang RS, Hsiao FY (2018) Effects of anti-osteoporosis medications on total hip arthroplasty risks in osteoporotic patients with hip osteoarthritis in Taiwan: a nationwide cohort study. Arch Osteoporos 13:107

30. Fu SH, Wang CY, Yang RS, Wu FL, Hsiao FY (2017) Bisphosphonate use and the risk of undergoing total knee arthroplasty in osteoporotic patients with osteoarthritis: a nationwide cohort study in Taiwan. J Bone Joint Surg Am 99:938-946

31. Neogi T, Li S, Peloquin C, Misra D, Zhang Y (2018) Effect of bisphosphonates on knee replacement surgery. Ann Rheum Dis 77:92-97 
32. Priemel M, von Domarus C, Klatte TO, Kessler S, Schlie J, Meier S, Proksch N, Pastor F, Netter C, Streichert T, Puschel K, Amling M (2010) Bone mineralization defects and vitamin D deficiency: histomorphometric analysis of iliac crest bone biopsies and circulating 25-hydroxyvitamin D in 675 patients. J Bone Miner Res 25: 305-312

33. (2019) Endoprothesenregister Deutschland (EPRD). Jahresbericht 2019. https://www.eprd.de/fileadmin/user_upload/Jahresbericht 2019_doppelseite_2.0.pdf
34. Klasan A, Baumlein M, Bliemel C, Putnis SE, Neri T, Schofer MD, Heyse TJ (2019) Cementing of the hip arthroplasty stem increases load-to-failure force: a cadaveric study. Acta Orthop 90:445-449

Publisher's note Springer Nature remains neutral with regard to jurisdictional claims in published maps and institutional affiliations. 